\title{
A Breath of Fresh Air: Absence and the Structure of Olfactory Perception.
}

\section{Tom Roberts}

(Forthcoming in Pacific Pbilosopbical Quarterly)

\begin{abstract}
The question of whether we can perceive absences, in addition to 'positives', has received recent attention in the literature on the nature of vision and audition. The aim is to demonstrate that there can be objectless forms of perceptual consciousness; specifically, to show that such episodes can be distinguished from those in which there is merely no perception at all. The current paper explores this question for the domain of olfaction, and argues that there can be experiences of the absence of odours, in addition to positive smell perception. Doing so sheds light upon the structure and spatial content of olfaction.
\end{abstract}

\section{Introduction}

O’Shaughnessy (2002) exemplifies a commonly-held view that perception is always of 'positives', never of absences. We perceive the objects, events, and properties that populate our physical surroundings, and which are the causes of our experiences. Recent work has challenged this framework in the visual and auditory modalities (Sorensen 2004, 2008a, 2008b; Soteriou 2011; Richardson 2010; Phillips 2013). Sometimes, for instance, it is appropriate to speak of holes and shadows as objects of vision; silence as an object of hearing. Physical entities, on such a construal, are no longer the only candidate participants in a subject's visual experience, nor sounds the only possible objects of audition: absence(s), too, can bear intentional and phenomenological significance.

In this paper, I explore how parallel considerations play out in the domain of olfaction, and argue that here, too, the absence of an odour can itself be an object of olfactory experience. In doing so, a number of lessons concerning the structure and content of olfaction can be drawn out. In particular, its spatial character; the extent to which the perception of smell is an embodied and enactive phenomenon; and the possibility of distinctive kinds of olfactory illusion. 


\section{Absence in vision and audition}

A central task faced by the proponent of absence-perception is to distinguish such episodes from those in which there is merely an absence of perception. What makes the difference, for instance, between seeing darkness and failing to see anything at all (Sorensen 2008a), or between the auditory perception of silence and deafness (Phillips 2013)? A brief examination of responses to these questions reveals the landscape of the debate that has played out between those who favour the idea of visual and auditory perception of absence, and those who oppose it.

One popular route towards understanding a subject's conscious awareness of absence is to appeal to structural features of the sensory modality in question: properties of experience, such as spatial and temporal characteristics, that are independent of any particular perceptual object. There is some consensus, for instance, that the structure of visual experience is such as to permit the perception not only of physical objects and their properties, but of empty spaces that are potential locations for such entities (e.g. Martin 1993; Nudds 2001). The spaces between and within the objects and surfaces we see are visible because we are aware of invariant properties of the visual field - the cone of space extending from the eyes - itself (Richardson 2010; Phillips 2013; both following Martin 1992), not as an object that we see, but in virtue of its providing structuring conditions for our experience of the world. We see the portion of the world in which things can be seen, in virtue of being aware of our own visual limitations: the cone of the visual field is experienced as a sub-region of a limitless, extended space of which the visual field is only a part. In being conscious of the boundaries of our current visual awareness, we are apprised of the space in which objects could be, but are not, located (Richardson 2010; Soteriou 2011). This awareness is independent of any object that happens to occupy a region of the visual field. Vacant spaces can be visually perceived, then, because structural properties of this modality make possible a distinctively visual experience even in the absence of the characteristic objects of vision. There is thus a sustainable distinction between the visual perception of absence and the mere absence of visual experience: because we are capable of experiencing spaces, we can 
successfully perceive a space as empty, rather than simply failing to experience that space at all (which is what happens when that space is out of sight).

In contrast to the visual modality, it has been argued that auditory perception lacks intrinsic spatial import (e.g. Nudds 2001, following Strawson 1959). Hearing, on this construal, does not present the world as a spatially extended arena for sounds or sound-possibilities: there is no 'auditory field', analogous to the visual one, within which distinct sounds are perceptually located. As a result, it is impossible to mark a distinction between hearing silence at a location, and failing to hear anything at all there (Nudds 2001: 213). Although we can be aware of the directional properties of sounds - for instance, that a voice is coming from one's left - we are never aware, on this view, of empty regions that are the possible locations of sound.

Several authors, however, have attempted to motivate the auditory perception of silence despite this modality's impoverished spatial content. Roy Sorensen (2008b) argues that the phenomenology of auditory experience, and common sense talk about its possible contents, vindicates the hearing of silence: ' $[\mathrm{A}]$ teacher can hear the silence of her classroom while also hearing a lawnmower outside... A conductor can hear silence from the left half of the choir while hearing the right half singing'. (2008b: 142). Sorensen defends this position by claiming that the spatial properties of silences are parasitic upon those of sounds, which have location and direction. Silence is the absence of acoustic waves, and is experienced where the waves would have been (2008b: 147). ${ }^{1}$

Ian Phillips (2013) adds two further considerations in support of the claim that absences of sound can be heard. Firstly, he highlights that pauses and endings of sounds, for instance those that punctuate successive movements of a piece of music, can be perceived. These are 'contrastive' cases of silence experience. By emphasising the extended duration of ordinary auditory experience, Phillips maintains, it can be shown that regions of time can be perceived as temporal spaces for possible sounds. The auditory 'hole' between two separate sounds - that constitutes a 
pause - can be heard in virtue of hearing the sounds themselves. ${ }^{2}$ Once again, on this analysis, there are structural features of auditory perception (features that are independent of any particular object of experience) that permit us to draw a distinction between absence-perception and absence of perception: in the former, but not the latter, there is an episode of awareness in which (temporal) portions of the world are present to the subject as locations for possible auditory objects. Soteriou (2013: 127) argues that this 'temporal sensory field' of audition is analogous to the spatial field of visual perception: whereas the former enables the subject to make contact with a region of space, the latter gives her an awareness of an interval of time. An account of this sort permits us to say, as is intuitively plausible, that the permanently deaf do not possess such awareness, and so need not be said to be continuously hearing silence. Finally, the contrastive account of silence perception does not force us to revise our standard view of the proper objects of audition: it is consistent with the claim that all episodes of auditory awareness involve experiences of sounds.

Secondly, Phillips draws attention to the distinction between hearing and listening, 3 in order to defend cases of non-contrastive silence experience (that is, absences that are not framed by particular noises against which the silence is juxtaposed). Following Moore (1903), Phillips suggests that states of conscious awareness can, in general, be decomposed into a unique element of awareness, plus a unique relation of that element to an object, and that the total qualitative character of the experience is determined by both of these constituents. An episode of visual consciousness, for example, is made up of a distinctive element of visual awareness, plus whatever qualitative character is added by the particular objects of the experience. Listening is to be understood as the element of pure auditory awareness that accompanies any episode of hearing: it is the 'activity of opening the attention to the influence of sound' (Phillips 2013: 35). Crucially for present purposes, the unique element of pure awareness can be dissociated from any object, and so be instantiated even in cases where there is an absence of the usual objects of a given modality. Thus, there can be instances of distinctive auditory consciousness (episodes of listening) even when this is unrelated to any sound in the environment. Phillips's analysis helps to 
explain the cases presented by Sorensen, too: the conductor, by making himself receptive to the left hand side of the choir, engages in an act of auditory awareness that is directed towards this collection of singers, and which permits him to hear their silence. ${ }^{4}$ As before, this is to analyse experience in terms that involve more than simply its objects; and any successful account of this sort will help to motivate the perception of absence, by enabling us to understand how awareness can be instantiated without being related to any particular object. If listening can occur even where no sounds are present, and this scenario can be distinguished from the case in which there is simply no auditory awareness at all, then we have the makings of an account of the auditory perception of silence.

Lastly, Farennikova (2013) has developed an account of absence-perception whose aim is to explain episodes in which particular perceptual objects are experienced as missing from a scene, such as one's visual encounter with a table that is unexpectedly empty of one's laptop. On this view, an absence experience is undergone when a mismatch occurs between a template generated in working memory - an image or expectation of the missing feature - and the perceptual feedback one receives from the world (p444). A visual search for one's laptop, for instance, is thwarted when that object is not where one anticipates, and this incongruity generates the phenomenology of absence. ${ }^{5}$ Although it is Farennikova's view that the more general cases considered by the theories outlined above (of silence or darkness, for example) are not genuine instances of absence perception, due to their not fitting the mismatch model, it is not clear that her position is really in conflict with those alternatives. We can think of them as distinct perceptual phenomena: on the one hand, conscious awareness of regions of spatial or temporal emptiness, and on the other hand, an experience as of a particular thing's absence.

\section{Epistemic perception of absence}

Before turning to the olfactory perception of absence, it is important to examine a further challenge to the notion that vacant spaces, pauses, and silences can be experienced in the way 
that ordinary objects and their features can. This is the accusation that such encounters are better thought of as instances in which the subject entertains a cognitive, rather than a purely perceptual, attitude towards the absence in question; that they are examples of epistemic seeing and hearing: ${ }^{6}$ seeing-that or hearing-that. Commentators writing in defence of the perception of absence tend to wish to avoid this conclusion, in large part because their thesis gains its philosophical interest from its raising the possibility of experiences that do not involve the ordinary objects of a given modality, an implication that can be resisted if the relevant states are merely epistemic. It is not, for instance, that the silence is a participant in auditory experience (a phenomenon that may require us to revise the view that all auditory perception is, or involves, the perception of sounds), but simply that the subject judges that she is in a sound-free situation, due to the absence of auditory input. On this account, there is nothing distinctively perceptual that marks out an absence experience from an absence of experience; only an occurrent cognitive attitude towards the negative-existential content in question. On O'Shaughnessy's view, an absence of auditory experience signifies an absence of sound in the environment, and an awareness of the former, when it is trusted by the subject, leads to a belief in the latter.

Some cases of absence-perception are, rather plausibly, best accommodated in epistemic terms. Where one sees a vacant space upon returning to where one had parked one's car, for example, it is natural to think of one's cognitive expectations as fixing an epistemic attitude towards this absence: one sees that one's car is missing. Similarly, in visually comparing two adjacent circles, only one of which houses a central dot, it is possible to see that the second circle is empty of a dot (Richardson 2010: 230). This occurrence, too, can be diagnosed by appeal to the expectations primed by the perception of the first circle, plus an inference to the effect that the dot is missing from the second. In auditory perception, the contrastive cases also appear to fit this model. The temporal intervals that are heard as empty are heard as empty of the particular sounds that form their sonic boundaries. This is borne out by the phenomenology of pause- and endingperception, which suggests that experiences of noiseless regions are not all qualitatively identical. The stark silence that marks the cessation of an overwhelmingly loud, clamouring noise is heard 
differently from the period of quiet that sits in the interlude between gentle, soothing tones. The ongoing expectations of the listener are surely responsible, in part, for this phenomenal difference, giving us reason to frame the auditory contrast cases in epistemic terms. ${ }^{7}$

Other absence experiences, however, appear to resist this analysis, and there are general reasons to believe that the epistemic conception places excessive demands upon subjects of experience. Judgements concerning spatial and temporal vacancies, and absences of particular phenomena about which one has expectations, require the subject to possess the conceptual repertoire necessary to articulate these contents. This, in turn, excludes non-concept-users, including animals and young infants, from having experiences of this nature. ${ }^{8}$ This is a counter-intuitive consequence, especially in light of the ecological significance that silences may have for perceivers in the wild (for example, a sudden hush that descends in the jungle). It is implausible even that adult perceivers are obliged to formulate a judgement about an absence in every case. Indeed, it is possible to conceive of scenarios in which a subject has an experience of an absence that she believes is not instantiated, as when noise-cancelling headphones are briefly donned in a crowded room. This possibility is not permitted by the epistemic conception: if the situation does not engender the inference that one is in a soundless environment, it can involve no more than an absence of auditory perception. Finally, it is possible to attend to absences (Phillips 2013: 336), in a manner that is difficult to square with the epistemic conception. Attending to a silence through listening - through priming one's sensitivity to possible sounds - appears to differ from the cognitive act of reflecting upon a negative-existential content.

Although these considerations are not decisive, they are enough to apply pressure upon the view that absence perception is really only a species of judging. The claim that I wish to pursue in the olfactory domain, following those proponents of the visual perception of holes and shadows, and the auditory perception of silences, is that the smelling of absences can proceed in straightforwardly perceptual terms, unreliant upon cognitive attitudes of the type espoused by the epistemic approach. 


\section{Smelling absences}

In visual and auditory perception, we saw that any account of the experience of absence is determined, at least in part, by what we take to be the respective perceptual objects of these modalities in ordinary cases. Visual absence experiences typically involve perceiving spaces as vacant of the normal objects of vision (physical entities), while auditory absence experiences present spaces as silent: free of sounds, the standard objects of hearing. ${ }^{9}$ For present purposes, I shall treat odours - collections of fragranced particles in the air - as the immediate objects of olfaction, and my primary concern will be to identify cases in which a subject undergoes an experience of, or as of, an absence of odour. ${ }^{10}$ I will consider briefly the further issue of whether physical objects that are the sources of odours also enter into the content of olfactory perception in section 6 below.

Although the topic has not received sustained attention, there is some resistance in the literature to the claim that absences of odours can be perceived in olfaction (e.g. Sorensen 2008b: 137), on the grounds that odourlessness matters only very little within the life of the human being. That a location or situation is smell-free, argues Sorensen, is of marginal ecological significance: the business of olfaction is to track threats and opportunities, typically of an organic nature, and the perception of positives (odours that characterise sources of food; suitable mates; deadly prey; and so on) exhausts this business.

I suggest, however, that there are instances of absence perception in olfaction that fit with our common sense understanding of this modality and its phenomenology; that involve odour-free characteristics that are ecologically and behaviourally rather salient; and that are permitted once we understand the structural properties of olfactory experience. The kinds of case that I have in mind, and which will be discussed in the following sections, tend to involve fresh air - for example, that which accompanies opening the window of a stuffy train carriage; that which is found in a receptacle that is free from contaminants; or that which fills an otherwise vacant 
room. Folk talk is congenial to the claim that odourless regions can be smelled, and also to olfactory correlates of Sorensen's choirmaster example: one can smell the open refrigerator as free from the odour of spilled milk, even while it contains the scent of mouldy vegetables. ${ }^{11}$ Moreover, to speak of olfactory absences as having only negligible significance for human projects and behaviour is to neglect, for instance, their ability to signal a lack of pollution; to enable us to keep track of where odorous entities have and have not been; and to give us relief from temporally extended bouts of positive, and perhaps unpleasant, olfaction.

Some possible olfactory absence experiences appear to mirror the structure of the contrastive cases of pause- and ending-perception in audition, although the temporal boundaries that mark the beginning and end of an olfactory 'hole' or 'edge' are blurred and drawn out in comparison to the often sharply defined dynamics of sound. It is possible to smell, for instance, the absence of a lingering odour that one has expected to find in a familiar location, or the welcome influx of fresh air that follows prolonged exposure to a foul effluvium. As in the auditory modality, too, not all encounters with odorless phenomena are qualitatively the same, but instead depend upon the contrastive odours by which they are framed: pungent scents leave a more salient odourabsence in their wake than do more delicate fragrances. ${ }^{12}$ In olfaction, one is aware of contrastive absences in virtue of perceiving their surrounding odours, and so they are consistent with the claim that all experiences within this modality have odours as their immediate objects.

Non-contrastive cases of olfactory absence experience are possible, too, and formulating the conditions under which these can be instantiated permits a clearer understanding of the structure and content of smell perception. The structural features of olfaction - elements of perceptual experience in this modality that are independent of any perceived odour - can be shown to be bound up with an integrated suite of embodied, structuring activities that provide background conditions for perceptual awareness of this kind. In what follows, I suggest that attending to the embodied character of olfactory experience, and to cross-modal contributions from vision and touch, provides an informative way of understanding absence perception in this modality, ${ }^{13}$ by 
showing how it is that olfaction presents us with regions of both space and time that are possible locations for odours.

\section{Embodiment and olfactory content}

Richardson (2013) has drawn philosophical attention to the significance of the act of sniffing for olfactory perception which, she argues, secures the exteroceptive nature of experiences within this modality. During inhalation, when chemical stimulants in the air are drawn into the nasal passageway, odours are experienced as entering the body from outside, and so not simply as located at or in the nose. ${ }^{14}$ The dependency between smelling and sniffing is given support by empirical studies which indicate that excitation of the olfactory epithelium (the region responsible for detecting odorous molecules) is on its own insufficient for an olfactory percept; only when air passes through the nasal cavity does the subject become consciously aware of the particles' odour (Mainland et al 2006). In addition, it has been shown that particular odour types tend to prompt sniffs of characteristic duration and intensity (Bensafi et al 2005) - pleasing odours are, predictably, sampled with more enthusiastic inhalations than are disagreeable ones - and that sniffing typically accompanies episodes of olfactory imagery (Bensafi et al 2003).

The embodied activity of sniffing presents odours as having some degree of spatial presence outside the agent's biological boundaries. The region of air around the perceiver is experienced as a location for odours: they are experienced 'here', or 'around me' (see, e.g., Batty 2010b; Matthen 2005: 284; Smith 2002: 144). Moreover, because inhalation has a certain duration, it makes the subject aware of a region of time as a potential location for smells - the temporal envelope that lasts for as long as air passes the nasal cavity. Sniffing thus provides the foundational element for the possibility of olfactory experiences of absence. An act of inhalation that draws in no discernible odour can nonetheless be identified as an episode of (objectless) olfaction in which the region around the perceiver is experienced as empty, for the duration of the sniff. ${ }^{15}$ Moreover, sniffing marks the distinction between the olfactory experience of absence and the 
mere absence of olfactory experience. When one holds one's breath, or has congested sinuses, one has no conscious awareness of smell, but this does not constitute an absence-experience, for no region is sampled as a possible location for odour. The same is true of the periods between breaths: we are not required to say that we continuously alternate between perceiving positives and negatives (a peculiar way of describing our ongoing olfactory awareness); rather, when exhaling we have no olfactory experience of the space around us. The odour-free sniff offers an awareness of a vacant spatiotemporal location: the absence of an odour here and now. On its own, then, the activity of sniffing grounds a somewhat limited spatial content in olfaction: the area in the vicinity of the agent's nose, within which odours are perceptually localised, is relatively indeterminate in cases of smell experience where there is a pervasive ambient odour. ${ }^{16}$ The absence experiences that odour-free sniffing makes possible are correlatively lacking in determinate spatial content: the region that is experienced as empty is often only vaguely circumscribed. However, to focus too closely upon examples of smells that fill a whole environment is to lose sight of the more determinate olfactory spatial contents that occur under a range of other real-world conditions. Reflection upon such cases reveals that the class of possible olfactory absence experiences is, similarly, wider than it might initially appear.

Firstly, consider that some odours arrive on the breeze, and are experienced as such. Directional ventilation can add a dimension of spatial content that is missing in olfactory encounters with static air, permitting the subject to smell where an odour is coming from. A scent that is carried by a current that is felt upon the left hand side of one's face can, plausibly, be perceptually localised to that direction, and likewise for air that comes through an open window, from a hairdrier, out of a punctured tyre, in the slipstream of a passing pedestrian and so forth. Although these perceptual contents are impoverished in comparison to the spatial fidelity of vision - there is, after all, no olfactory field within which different odours are determinately located - they indicate the possibility of directional smelling. ${ }^{17}$ They are encounters with scented air that is experienced as arriving from a place or direction, and not simply as entering the body from outside due to inhalation. This lesson carries over to absence experiences, too: a current of fresh 
air, carving a hole through an aromatic atmosphere, can yield the perception of directional absence (ie. the experience of no-odour arriving from a direction) in appropriately sensitive subjects. It is possible to understand this directional olfactory content on the model of Evans's (1982: 154) treatment, according to which an experience's spatial content consists in its connections to a complex network of action tendencies. ${ }^{18}$ To perceive an odour as coming from the left, for instance, is to be disposed to orient one's body in that direction, to point or turn towards it, to look leftwards in pursuit of its source, and so forth.

Relatedly, the embodied subject's sensorimotor skills and expectations are more generally capable of contributing to the spatial content of her olfactory experiences, and of permitting her to attend to particular objects. Sensorimotor accounts of experience (e.g. Noë 2004), for example, conceive of perception as being essentially active, and mediated by an implicit understanding of the sensory consequences of movement. While this approach has received sustained criticism (e.g., Humphrey 2001; Campbell 2008; Martin 2008), and may do little to explain the overall quality or content of olfactory states, the exploratory nature of certain smell-involving episodes suggests that attention should be paid to sensorimotor considerations in this modality. The familiar model of smell perception that takes as canonical the inert perceiver located within an odour-filled habitat ${ }^{19}$ neglects the myriad subtle ways in which skilled agents probe and explore their sensory environment and anticipate the olfactory feedback they will receive in return. The activity of olfaction is often an ongoing and dynamic enterprise (see, for example, Gibson 1966; O'Dea 2011; Cooke \& Myin 2011). Perceivers bring items to the nose for sampling, and bring the nose to possible sources of odour to test and investigate their qualities. Scents afford behavioural reactions of attraction and repellence, of interrogative insufflation, and of purposeful regulation and maintenance (such as wafting, fanning, or nose-holding). While sniffing alone provides the subject with an awareness of the qualities of surrounding air, the conjunction of sniffing with embodied exploration enables multi-modal perceptual examination of more tightly specified regions of space, including object surfaces, cavities, receptacles, and the like. Upon bringing the mouth of a milk bottle to one's nose for testing, it is the visually encountered space inside this 
container - and not simply some nebulous 'here' surrounding one's head - that is the perceived location of any encountered odour. Similarly, one can sniff each of one's fingers in turn, to detect which is the location of a residual odour after hand-washing, for instance. Non-human animals are surely expert in activities of this form as well; the performance of dogs trained for search and rescue being one such example. ${ }^{20}$

The conception of olfaction as an embodied, active, and exploratory procedure that is integrated with our other sensory powers lends support to the analysis of the senses provided by Nudds (2001), upon which our experience of the world is essentially multimodal. Whereas there is a natural tendency to think of the senses as 'five different perceptual inlets to the mind... distinct from and independent of the rest [and] that our perception of the world is the result of the combined use of whatever senses we have, so that what we perceive is the sum total of what each sense provides' (p224), this understanding of experience as fragmentary fails to do justice to the ways in which the perceptual modalities work in concert to provide a phenomenological unity, as of an external world that is populated by objects that are capable of bearing a whole range of perceivable properties. For Nudds, this lesson is reached by attending to the bi-modal character of our experience of the production of sounds, during which auditory and visual modalities function in unison and we hear sounds as produced by the objects that we see. A similar conclusion can be drawn from consideration of olfaction: sniffing involves the combination of tactile, proprioceptive, trigeminal, and olfactory activity, whilst the exploration of surfaces and cavities, and the tracking of directional air movement are essentially bodily. ${ }^{21}$ The senses cooperate to present odours as substantive parts of our material habitat - borne on air that surrounds, fills, and traverses the familiar spaces we encounter. Attempting to answer the question of whether olfaction 'alone' can deliver richly spatial contents is thus to miss the point: we experience odours as being located in, or coming from, the spaces that we see and feel.

Spatial contents like those of the milk bottle case apply equally when what is experienced is an absence of smell, and we can conceive of sensorimotor routines as structuring features of olfaction - attributes of a perceptual encounter with the world that can be identified as 
characteristic of this modality, but which are independent of any particular object of experience. The subject who grasps and sniffs the open bottle puts into play a suite of integrated perceptual skills, even when their outcome is an encounter only with fresh air. The embodied activities, and their multi-modal components, make the subject aware of a region of time and space that is a potential location for odours. Olfaction, in co-operation with vision and touch, is capable of presenting portions of the world in a way that is independent of any odour that may be found there. Positive olfaction involves a conscious awareness of odours as located in time and space, while olfactory experience of absence involves making perceptual contact with those regions and finding them empty. If all of one's fingers are clean, for example, then one will experience an absence of odour at the location of each one in turn. Searching for one's glass at a party, one may smell a sequence of absences in successive empty goblets before hitting on one's own, winetinged vessel. Discoveries of this nature are apt to elicit distinctive behavioural responses, and properties such as cleanliness that are signified by odourlessness may have ecological significance, defying the assertion that we are indifferent to odour absences.

Without airflow through the nose, smell sensations (if they were empirically possible under these conditions) would have no exteroceptive quality - their experienced locations would be like those of pains or itches. Without being able to integrate olfactory stimuli and tactile information from the skin, it is likely that smells could not be perceptually localised to directions when they are carried on felt airflow. Without the ability to explore the environment by moving one's nose and manipulating objects, smells could not be perceived as being housed within confined spaces. These embodied capacities, then, enrich the spatial significance of olfaction, and make it possible to understand how absence experiences can occur in this modality by providing structuring conditions enabling odourless olfactory perception.

A question remains as to whether the emphasis placed upon an agent's embodied activities is really necessary to accommodate the structural features of olfaction, or if the work is done, instead, by multi-modal effects that are, strictly speaking, independent of exploratory movement. 
It is possible, after all, to conceive of a creature who lacks the right kinds of embodied skills, finding herself unable to control which items she encounters at the nose, but who is nonetheless able to see and feel the sources of odours, and it seems that this individual could be party to the cross-modal co-operation required for the spatial contents outlined above. Two responses can be made on behalf of the embodied approach here. Firstly, we might treat these as a set of contingent claims about human olfaction: that, for creatures like us, the perception of odours as being located within, or as coming from, determinate spatial regions is a multi-modal phenomenon that is mediated by bodily skills of exploration. Secondly, and perhaps more interestingly, we can appeal to embodied expertise in explaining what it is for a subject to open her attention to the influence of odour - ie. to treat it as part of an olfactory equivalent of listening. Recall that the power to listen - 'a doing that is specifically apt for generating sound to cause hearing of itself (Phillips, 2013: 357) - is said to distinguish between those who possess, and those who do not possess, an auditory stream of consciousness, and so to mark the difference between those who can experience silence and those who cannot. Experiencing silence is opening one's attention to the influence of sound, and receiving nothing in return. In olfaction, we can point to embodied skills - of targeted sniffing, the bringing of items to the nose, wafting, and so forth - as activities that are specifically apt for generating odour to cause smelling of itself. That is, these behaviours provide causal impetus for odours in the environment to be picked up by the agent's olfactory mechanisms. As in the auditory case, we can assess whether a subject is capable of olfactory absence-experience on the basis of whether she can open her attention to the potential influence of odours. Consider an individual who suffers from long-term anosmia, a perceptual deficit resulting in impaired olfactory sensitivity. Just as it is counter-intuitive to say that the blind permanently see darkness, or that the deaf always hear silence, so it is not plausible to treat the anosmic as a constant subject of olfactory absence-experience. We can now avoid this implication by saying that, over time, this subject has lost her dispositions to enact her embodied olfactory skills, having come to know that they won't deliver any positive conscious awareness of odour. In virtue of this, she no longer has an olfactory stream of consciousness, capable of presenting regions of time and space as full, or as empty, of odour. 


\section{Source-object perception}

Up to now, my attention has been restricted to scenarios in which the olfactory subject is perceptual witness simply to an absence of odour in some portion of air-filled space during the duration of a sniff, just as positive olfaction tracks fragrant particles in such regions. There is little firm consensus over whether olfactory perception is also capable of representing those physical objects that are the sources of odour (for contrasting views see, e.g, Lycan 2000; Batty 2010a), and I will not attempt to settle this debate, but it is worth noting briefly here that our answer to this question has implications for the possible contents of olfactory absence experiences.

On a common way of speaking, we can experience ordinary objects and their properties by, or in virtue of, smelling their odours. We perceive a cup of coffee, in olfaction, by perceiving the plume of odorous molecules it emits into the air; we smell the saltiness of the ocean by inhaling its saliferous scent, and so forth. If this is true, then we might also expect to be able to perceive a source object or property's absence in virtue of perceiving an absence of its odour. Contrast this with the auditory modality. Here, Phillips's Moorean analysis provided preliminary resources to explain how a subject might perceive the silence of a particular physical entity: in listening to (or for) an object, one directs one's auditory attention towards it, irrespective of its occurrent sound emission. An auditory expert, such as a choirmaster, can thus perceive the silence of the soprano section, for example, amidst the noise of the wider ensemble.

A similar story can be told for olfaction, and once again the agent's embodied skills are naturally understood as playing a role in empowering the direction of olfactory attention towards a particular target. By bringing her nose to the surface of an object, an individual can perceive its odourlessness, just as she might experience an item's positive olfactory qualities in an equivalent manner. In addition, the source-smelling model allows us to speak of the olfactory perception of an absence of certain ordinary objects, in a way that fits with common-sense talk. An absent- 
minded chef may sniff his casserole to check whether he has forgotten any ingredients, and perceive an absence of oregano in virtue of smelling an absence of its distinctive bouquet. Thus, if we accept the account of odour-absence perception offered above, the lessons of this treatment transfer to permit the olfactory perception of particular source objects and properties.

\section{Epistemic olfaction}

The challenge remains to defend the possibility of olfactory absence perception against the epistemic-perceiving objection: why should we think that the cases I've mentioned are strictly perceptual, rather than involving simply a cognitive attitude to the effect that no olfactory object is present? Some permissible positive contents of olfaction are indeed suited to the epistemic description - an individual can smell that the toast is burning, or that this glass had orange juice in it. Certain olfactory absence encounters, too, may be best understood as involving attitudes of belief, especially those of a contrastive nature. Where a scent is swept from the room by an influx of fresh air, one may smell that it is gone; and when one is expecting a familiar aroma, one may perceive that it is absent. In both cases, one formulates the judgement that the environment does not contain some particular odour, and this requires one to have conceptualised that olfactory phenomenon. $^{22}$

Elsewhere, though, smelling an absence does not appear to demand the deployment of conceptual resources which, after all, are likely to be available only to adult human perceivers. The structural features of olfaction emphasised above can be shared by non-concept-using individuals. Sniffing air that bears no odorous molecules need not be a reflective activity, while enactive theories hold that sensorimotor capacities and expectations need not require explicit conceptual knowledge. Instead, they are skilful abilities to move one's body, coupled with an implicit command of these movements' sensory consequences; an understanding, for example, that an odour will diminish in intensity as one recedes from its source, or that bringing one's nose to an aperture will enable one to detect the scent that passes through it. The sensorimotor 
abilities peculiar to olfaction can be brought into play both where the subject has no wellarticulated belief about the odours in her vicinity, and where there is a belief that is in fact contrary to what is delivered in perception. Consider someone prone to short and sudden bouts of complete anosmia. Sniffing the space around her and receiving no positive olfactory feedback, this individual may not be able to tell whether she is currently afflicted by a loss of her sense of smell, and so have an experience of absence without a correlative belief as to whether her surroundings are actually vacant of odours. Encountering a coffee percolator, she may explicitly judge that its aroma fills the room, while nonetheless undergoing an experience of olfactory absence. If such scenarios are possible, then there is reason to believe that the cognitive states demanded by the epistemic conception of perception are not a necessary component of absence experience in olfaction.

A related cognitivist objection can be leveled against the claim that the content of olfaction is capable of specifying determinate regions of space, or directions, in virtue of the cross-modal contribution of vision or touch. Why not think, instead, that we come to a post-perceptual judgement to the effect that odours are located where such spaces are seen, or are arriving from a felt direction? While a full examination of multi-modal effects is beyond the scope of the current discussion, there are reasons to believe that here, too, the cognitivist view is to be resisted. First, the phenomenology of such episodes does not appear to support this alternative, which holds that distinct sensory channels deliver distinct perceptual experiences, the co-occurrence of which inspires the judgement in question (for instance, that there is visual awareness of the mouth of a bottle, simultaneous olfactory awareness of a scent, plus an inference to the belief that the latter emanates from the former). It is not clear that separate olfactory, visual, and tactile elements can be phenomenological decomposed in this way; instead, a multi-modal episode seems to generate an integrated conscious awareness as of a world of material entities and their properties. Open the window, and put your nose to where the breeze carries in the smell of fresh-mown grass. It is not at all easy to isolate a distinctly tactile phemomenal character on the one hand, and a purely olfactory experience on the other. The mown-grass scent does not appear to be detached from 
what is felt; it appears to be carried on the air. To think otherwise is to treat odours as, from the point of view of perception, not fully a part of the physical environment. Moreover, if we are convinced by the plausible claim that olfaction is exteroceptive, the cognitivist view must say that even though the odour is experienced as drawn in from a region in which a seen or felt object, aperture, or cavity is located, it is nonetheless not perceived as coming from, through, or out of these features, but is only attached to them in thought. Again, it does not feel as though such contents are entertained in (conscious) thought, and nor is it plausible to exclude those creatures who lack the conceptual resources to make such judgements from being possible subjects of multi-modal episodes of these kinds. ${ }^{23}$ An account of the senses which treats them, in general, as distinct channels of input with distinct conscious outcomes is not mandatory, and if we accept that it is the function of our perceptual systems to operate in concert with one another in order to deliver unified experiences of the things we encounter, then finding that olfaction exhibits multi-modal co-operation should not be unexpected.

\section{Perceptual error}

By permitting the olfactory awareness of absence, we raise the possibility of hithertounconsidered cases of perceptual error, in which the absence experience does not match the state of the world. Whether there are examples of both illusions and hallucinations of absence depends, once again, upon how we understand the ordinary contents of olfactory awareness. Batty (2010a) argues that the ordinary distinction between illusion and hallucination fails to apply in the olfactory modality, on the grounds that smell experiences do not depict objects as bearing particular features, but only present odourful properties as being instantiated in the region near the nose. If this is correct, then there is no way to clearly distinguish illusions, in which an object is perceived as having a property that it does not possess, from hallucinations, in which a nonexistent object is perceived as having certain features. On Batty's analysis, the content of positive odour experiences is 'weak and abstract', and indexical - odours are experienced as being instantiated 'here', with no further spatial determinacy. Olfaction does not attribute properties to 
particular objects, on this view, and so perceptual errors of positive olfaction thus involve experiencing an odour only as having been instantiated when it has not been, and should thus be considered as instances of what Batty terms 'property hallucination': the mistake is not in perceptually attributing the odour to a non-existent object, but simply in experiencing a scent that is not there at all. Batty's account is consistent with the possibility of olfactory absence perception, but only of similarly 'weak and abstract' absences - a lack of odour 'here'. This can be in error only when there is no odour absence here - if, instead, there is a pervasive scent filling the space around one.

We saw above, though, that it is not obligatory to restrict the contents of olfactory experiences to those of only a weak and abstract nature. Smell perception can track the direction from which some odours arrive, and it can investigate determinate regions of space, such as those around, on, or inside objects, when integrated with bodily activities. Adopting this view, we can see that there is a greater range of possible odour illusions than is countenanced by the austere account of olfactory content. Illusions of positive odours come in several kinds, corresponding to the various contents made possible by the subject's embodied skills. Most straightforwardly, a region of space may be experienced as containing an odour that is different from the one it actually houses; the phantosmia that sometimes accompanies a migraine being one such example. ${ }^{24}$ But an olfactory experience can go awry with respect to its directional or spatial content, too. Consider a subject who, unbeknownst to her, has had a pungent compound smeared beneath her nostrils while asleep. Upon waking, she feels a current of air upon her face, from an open window. When she inhales, I submit, she may experience the unguent's odour as coming through the window from outside. Similarly, if she sniffs the mouth of an empty bottle, she is likely to perceptually misattribute the odour to the inside of this container. ${ }^{25}$ Perceptual errors of olfactory absence experience are possible, too. An illusion of absence occurs only when there is an odour within a perceived space, but the subject experiences that space as empty. The temporary anosmic, for example, is capable of episodes of this sort, due to her inability to detect the odours that she draws in. 
Hallucinations of absence, however, are more difficult to conceptualise, and they rely upon there being olfactory experiences that do attribute properties to source objects (contra Batty's position). The clearest examples are those which rest on the possibility of certain multimodal phenomena. Firstly, consider the hypothetical case in which a subject undergoes a rich hallucinatory experience as of having inhaled a gust of fresh air (a multi-sensory state involving bodily and trigeminal phenomenology, and apparent expenditure of effort), when in fact she has not sniffed at all. Under these conditions, she experiences as empty a region of space that she has not actually perceived. Secondly, consider the scenario in which I have had my index-finger amputated, but experience a vivid phantom digit in its place. With my eyes closed, and sniffing each of my (clean) fingers in turn, I experience the index finger as free from any odour. These cases, I suggest, are (as close as we can get to) examples of an olfactory hallucination of absence. Without the integration of olfactory information with that from the other senses, to provide a perceived object, the notion of a hallucination of absence is difficult to sustain in this modality.

\section{Conclusion}

Olfaction is not always the perception of odours, nor always the perception of objects in virtue of the perception of odours; sometimes, it is of absences. In this modality, as in vision and audition, there is a principled distinction to be drawn between experiencing an absence at some location, and simply failing to experience anything there. There are structural features of olfaction that make it possible to have objectless perception in this modality. We fail to smell anything at a place - over our shoulder, for example - when we fail to access it in the ways characteristic of olfaction. But we experience an absence of the ordinary objects of smell perception when we put into play our embodied olfactory skills and understanding to discover that some region of the world is empty. These discoveries can have non-negligible effects upon our ongoing goaldirected behaviour, just as the experience of silences, holes, and shadows can do. 
Some olfactory experiences of absence appear to be contrastive, in a manner similar to that of auditory awareness of pauses and cessations: they rely upon the perception of surrounding (typically, preceding) smells that frame some envelope of time as empty. In other cases, the odour-absence is not perceived in virtue of an awareness of boundary-providing contrasts, but is itself presented to the subject as a distinctive result of her olfactory investigation. The content of an absence experience can dissociate from that of the subject's judgements about the qualities of surrounding air, and so we need not conceive of such episodes only in epistemic terms. Finally, it follows from the possibility of olfactory absence experience that there can be perceptual illusions of absence, in which an area is perceived as fresh when it is in fact odorous.

The significance of the possibility of absence experience is twofold. Firstly, objectless consciousness reveals a sensory modality's invariant, structural properties. The structure of the visual field is highlighted by the fact that empty spaces can be seen, while silence perception teaches us that audition is capable of presenting regions of time as vacant or full. Olfactory awareness of absence is a phenomenon that forces us to pay attention to the active and embodied character of this modality - the features that make possible any conscious perception of odours as being housed in times and places. Secondly, objectless consciousness provides a counterexample to the claim that we can distinguish the senses purely in terms of their proper objects. Silence disproves the rule that we hear only sounds; holes and other voids challenge the view that what we see always has a colour. Fresh air provides the exception to any theory that holds that that olfaction is a simple relation between subject and odour. ${ }^{26}$

Department of Sociology, Philosophy, and Anthropology University of Exeter

\section{REFERENCES}

Batty, C. (2010a), "What the Nose Doesn't Know: Non-Veridicality and Olfactory Experience", Journal of Consciousness Studies, 17(3-4), 10-27. 
Batty, C. (2010b), "A Representational Account of Olfactory Experience", Canadian Journal of Philosophy, 40(4), 511-538.

Bensafi, M., Porter, J., Pouliot, S., Mainland, J., Johnson, B., Zelano, C., Sobel, N. (2003), "Olfactory activity during imagery mimics that during perception", Nature Neuroscience, 6, 11421144.

Bensafi, M., Pouliot, S., Sobel, N. (2005), “Odorant-specific patterns of sniffing during imagery distinguish 'bad' and 'good' olfactory imagers", Chemical Senses, 30, 521-529.

Briscoe, R. (2008), "Egocentric Spatial Representation in Action and Perception", Philosophy and Phenomenological Research, 79(2), 423-460.

Campbell, J. (2008), "Sensorimotor Knowledge and Direct Realism", Philosophy and Phenomenological Research, 76(3), 666-673.

Cooke, E. \& Myin, E. (2011), "Is Trilled Smell Possible? How the Structure of Olfaction Determines the Phenomenology of Smell", Journal of Consciousness Studies, 18(11-12), 59-95.

Dretske, F. (1969), Seeing and Knowing, London: Routledge and Kegan Paul.

Evans, G. (1982), The Varieties of Reference, edited by J. MacDowell, Oxford: Clarendon Press.

Frasnelli, J., Charbonneau, G., Collignon, O., \& Lepore, F., (2009), "Odor Localisation and Sniffing", Chemical Senses, 34(2), 139-144.

Gibson, J.J. (1966), The Senses Considered as Perceptual Systems, Boston: Houghton Mifflin.

Grice, P. (1962), "Some remarks about the senses". In Analytic Philosopby, edited by R.J. Butler, Oxford: Basil Blackwell.

Grush, R. (2007), "Skill Theory V2.0: Dispositions, Emulation, and Spatial Perception", Synthese, 159(3), 389-416.

Humphrey, (2001), "Doing it my way: Sensation, perception - and feeling red", Behavioural and Brain Sciences, 24, 987.

Kobal, G., Van Troller, S., \& Hummel, T. (1989), "Is there directional smelling?", Experientia, 45, 130-132.

Lycan, W. (2000), "The Slighting of Smell", in N. Bhushan \& S. Rosenfeld (eds), Of Minds and Molecules, 272-290. Oxford: Oxford University Press.

Mainland, J. \& Sobel, N. (2006), "The sniff is part of the olfactory percept", Chemical Senses, 31, 181-196.

Martin, M.G.F. (1992), "Sight and Touch", in The Contents of Experience, edited by T. Crane, Cambridge: Cambridge University Press.

Martin, M.G.F. (1993), "Sense modalities and spatial properties", in B. Brewer, R. McCarthy, and N. Eilan (eds), Spatial Representation, Oxford: Blackwell.

Martin, M.G.F. (2008), "Commentary on Action in Perception", Philosophy and Phenomenological Research, 76(3), 674-681.

Matthen, M. (2005), Seeing, Doing, and Knowing: A Philosophical Theory of Sense Perception, Oxford: Clarendon Press.

Matthen, M. (forthcoming), "The Individuation of the Senses", in M. Matthen (ed), The Oxford Handbook of the Pbilosopby of Perception, Oxford: Oxford University Press.

Mole, C. (2010), "The Contents of Olfactory Experience", Journal of Consciousness Studies, 17 (1112), 173-179.

Moore, G.E. (1903), "The Refutation of Idealism”, Mind, 12, 433-453.

Noë, A. (2004), Action in Perception, Cambridge, MA: MIT Press.

Nudds, M. (2001), "Experiencing the Production of Sounds", European Journal of Pbilosophy, 9, 210-229.

O'Callaghan, C. (2011) "On Privations and Their Perception”, Acta Analytica, 26 (2), 175-186.

O'Dea, J. (2011), "A proprioceptive account of the senses", in F. Macpherson (ed), The Senses: Classical and Contemporary Philosophical Perspectives, Oxford: Oxford University Press.

O'Shaughnessy, B. (2002), Consciousness and the World, Oxford: Oxford University Press.

Phillips, I. (2013), "Hearing and Hallucinating Silence", in F. Macpherson \& D. Platchias (eds), Hallucination, MIT Press.

Richardson, L. (2010), “Seeing Empty Space”, European Journal of Philosophy, 18(2), 227-243.

Richardson, L. (2013), "Sniffing and Smelling", Pbilosopbical Studies. 162(2), 402-419.

Schellenberg, S. (2007), “Action and Self-Location in Perception", Mind, 116(463), 603-632.

Smith, A.D. (2002), The Problem of Perception, London: Harvard University Press. 
Sorensen, R. (2004), "We See in the Dark", Noûs, 38, 456-480.

Sorensen, R. (2008a), Seeing Dark Things: The Philosophy of Shadows, Oxford: Oxford University Press.

Sorensen, R. (2008b), "Hearing Silence", in M. Nudds \& C. O'Callaghan (eds), Sounds and Perception: New Philosophical Essays, New York: Oxford University Press.

Soteriou, M. (2011), "The perception of absence, space, and time", in N. Eilan, H. Lerman, \& J. Roessler (eds), Perception, Causation, and Objectivity, Oxford: Oxford University Press.

Soteriou, M. (2013), The Mind's Construction: The Ontology of Mind and Mental Action, Oxford: Oxford University Press.

Strawson, P. (1959), Individuals, London: Methuen.

Teghtsoonian, R. \& Teghtsoonian, M. (1982), "Perceived effort in sniffing: the effects of sniff pressure and resistance", Perception and Psychophysics, 31, 324-329.

Teghtsoonian, R. \& Teghtsoonian, M. (1984), “Testing a perceptual constancy model for odor strength: the effects of sniff pressure and resistance to sniffing", Perception, 13, 743-752.

Wright, B. (2011), "Darkness Visible?", Australasian Journal of Philosophy, 90(1), 39-55.

${ }^{1}$ Note that Sorensen's account does not so clearly make reference to structural features of audition.

2 To deny this, argues Phillips, is to hold to an overly-austere 'snapshot' conception of experience, on which it makes sense to talk of instantaneous time-slices of qualitative character.

${ }^{3}$ We find a similar move in Grice 1962; and taken up by Matthen, forthcoming.

${ }^{4}$ Nudds 2001 holds that our experience of sounds as part of the material world is an essentially bi-modal phenomenon: we hear sounds as being produced by visible objects or events. If this is right, we can understand the conductor as hearing the left hand side of the choir producing no sound. I shall consider multimodal aspects of olfactory perception below.

${ }^{5}$ See Farennikova (2013) for further details of how the account is to accommodate cases which lack a conscious or deliberate perceptual search procedure.

${ }^{6}$ The idiom owes to Dretske 1969; see O'Shaughnessy 2002: 333-4, for a defence of the epistemic conception of hearing silence and other absences.

${ }^{7}$ Farennikova's mismatch model offers an alternative explanation of these kinds of case, by denying that the contribution of perceptual expectations, or templates, entails that the subject must draw an inference to the effect that an absence has occurred. For present purposes, I will concede as much as possible to the proponent of the epistemic view.

8 O'Shaughnessy (2002: 329) explicitly accepts that animals cannot hear silence.

${ }^{9}$ O'Callaghan (2011) raises a series of difficult metaphysical and perceptual questions concerning the status of absences of these sorts. I shall not attempt to address these in the current discussion.

10 I restrict my attention in this way firstly because this will be enough to show that the common view, that all episodes of olfaction involve perception of an odour, is false, and secondly to provide the clearest contrast case with absence experience in the other modalities.

11 The possible spatial contents of olfaction will be considered in detail below, alongside the claim that olfaction is capable of presenting regions of time as potential locations for odours.

12 There is an essentially affective element to the phenomenal character of certain olfactory experiences, too: smells can be disgusting, refreshing, pleasing, and so on. This feature is shared, at least to an extent, by the awareness of odourlessness, which can evoke emotional responses such as relief and delight. This contrasts with Sorensen's (2008b: 138) claim that odourlessness is 'emotionally flat'.

13 This is not to rule out the possibility that traditional, disembodied accounts of olfaction are also capable of accommodating these phenomena.

14 As Richardson notes, it may be that puffing air through the nostrils, without the deliberate inhalation of the subject, is sufficient for exteroceptive experience in this modality. Here, the perception of the odour as entering from outside the body would be secured by the tactile 
awarenss of airflow through the nose. If so, then the role of active sniffing is a contingent one, and the claims that follow can be read as an account of how olfaction works in ordinary human perception.

${ }^{15}$ Note that it may be possible to conceive of a creature whose olfactory experience presents odours in time but not in space. That is, there seems to be nothing conceptually impossible about a non-exteroceptive olfactory experience.

16 Richardson suggests that we can think of the spatial significance of olfaction as comparable to that of the tactile perception of heat and cool, which are felt as being outside the body but with little spatial acuity.

17 Existing empirical studies (e.g. Kobal et al 1989; Frasnelli et al 2009), indicate a limited human capacity for directional smelling, enabled by trigeminal nerve stimulation. However, these have examined only whether the subject can tell which nostril is being stimulated when an odour is fed to the nose, and not the wider ventilation scenarios. Why should we call such cases olfactory experiences with directional content? I suggest that it isn't possible to conceptually or phenomenologically decompose the total experience into olfactory and tactile components, as we would have to do in thinking of the experience as a smell sensation plus an awareness of air on the face. There is no 'pure olfactory sensation' that is left over once we subtract the putative tactile component in our imagination; nor does the total experiential outcome seem to be an inference from two modalities' outputs.

${ }^{18}$ For detailed discussion, see, e.g., Grush (2007), Briscoe (2008).

${ }^{19}$ Mole (2010) calls these 'pungency cases', and holds, as I do, that recent literature on smell perception has been overly restrictive in directing its attention to examples with this structure.

${ }^{20}$ Chrysippus's dog, who is alleged by the Ancients to have reached the intersection of three roads, sniffed two and found no trace of his quarry, before taking the third without sniffing, may be an example of animal absence-smelling.

${ }^{21}$ We can treat olfaction as multi-modal even if we hold that it is the felt flow of air through the nose, rather than the act of sniffing per se, that is key to its exteroceptivity.

22 Again, this is to concede as much as possible to the proponent of the epistemic conception. It may be that we can give a non-concept-involving account of these expectations, as we can for the more clearly sensorimotoric experiences, for example by appeal to Farennikova's 'templates', which are subpersonal representations of possible external features.

${ }^{23}$ For extended discussion of the cognitivist alternative, see Richardson 2013, section 6.

${ }^{24}$ See Mole (2010) for further examples of this sort; this element of my discussion draws closely upon his analysis.

${ }^{25}$ It is my intuition alone that corroborates this claim; it would be interesting to investigate cases of this sort empirically.

${ }^{26} \mathrm{My}$ thanks to an anonymous referee, whose comments on an earlier draft have improved the paper, and to Giovanna Colombetti and Dave Ward for helpful input. This work has been funded by the European Research Council under the European Community's Seventh Framework Programme (FP7/2007-2013), project title "Emoting the Embodied Mind (EMOTER)", ERC grant agreement 240891. 